\title{
Práticas Corporais de Aventura: uma experiência do PIBID Educação Física
}

\author{
Luciana Toaldo Gentilini Avila* \\ Cláudia Lima de Souza** \\ Rogerio Matias Soares ${ }^{* * *}$ \\ Nathalia Coelho Botelho**** \\ Lara Silva Schuerne ${ }^{* * *}$ \\ Sherelise Alves Duarte ${ }^{* * * * *}$ \\ Leonardo de Souza Rodrigues* \\ Joana Barroco Pinto" \\ Andre Luis Martins Pinto"
}

\begin{abstract}
Resumo:
O objetivo deste trabalho será o de apresentar as percepções de licenciandos em Educação Física sobre o processo de ensino e de aprendizagem do conteúdo Práticas Corporais de Aventura a alunos dos anos finais do Ensino Fundamental. Trata-se de um relato de experiência de uma proposta de sistematização das Práticas Corporais de Aventura elaborada e planejada de forma colaborativa entre dez estudantes de um curso de Licenciatura em Educação Física de uma Universidade Federal brasileira, bolsistas do Programa Institucional de Bolsas de Iniciação à Docência, e dois professores. A aplicação desse conteúdo se deu em turmas de 6ㅇ e 7o ano do Ensino Fundamental em uma escola pública. 0 resultado da experiência obtida nesse processo gerou três categorias: facilidades e dificuldades para o ensino, experiências com o ensino das Práticas Corporais de Aventura e aprendizagem dos alunos.
\end{abstract}

\section{Palavras-chave:}

Práticas Corporais de Aventura. Educação Física. PIBID. Escola.

\footnotetext{
* Doutora em Educação pelo Programa de Pós-Graduação em Educação da Universidade Federal de Pelotas, docente do Instituto de Educação/curso de Licenciatura em Educação Física da Universidade Federal do Rio Grande, leciona as disciplinas de Estágio Supervisionado, Pedagogias da Educação Física e Natação. E-mail: lutoaldo@msn.com. ORCID iD: http://orcid. org/0000-0002-8559-7904.

** Graduanda do curso de Licenciatura em Educação Física da Universidade Federal do Rio Grande. E-mail: claudiasouza93@ outlook.com.br. ORCID iD: http://orcid.org/0000-0002-5730-9012.

*** Graduando do curso de Licenciatura em Educação Física da Universidade Federal do Rio Grande. E-mail: rogerio81642016@ yahoo.com. ORCID iD: http://orcid.org/0000-0003-3722-4369.

**** Graduanda do curso de Licenciatura em Educação Física da Universidade Federal do Rio Grande. E-mail: nathaliac.botelho@ hotmail.com. ORCID iD: http://orcid.org/0000-0002-8143-5449.

***** Graduanda do curso de Licenciatura em Educação Física da Universidade Federal do Rio Grande. E-mail: lara.schuerne@ hotmail.com. ORCID iD: http://orcid.org/0000-0002-0285-7222.

****** Graduanda do curso de Licenciatura em Educação Física da Universidade Federal do Rio Grande. E-mail: sherelise. duarte16@gmail.com. ORCID iD: http://orcid.org/0000-0002-1600-0684.

******* Graduando do curso de Licenciatura em Educação Física da Universidade Federal do Rio Grande. E-mail: leonardosrds98@ gmail.com. ORCID iD: http://orcid.org/0000-0001-5552-7000.

******** Graduanda do curso de Licenciatura em Educação Física da Universidade Federal do Rio Grande. E-mail: joanabarrocop@gmail.com. ORCID iD: http://orcid.org/0000-0002-9598-123X.

********* Graduando do curso de Licenciatura em Educação Física da Universidade Federal do Rio Grande. E-mail: pintoandre1977@gmail.com. ORCID iD: http://orcid.org/0000-0002-1773-5877.
} 


\begin{abstract}
:
The aim of this work will be to present the undergraduate Physical Education students' perceptions about the process of teaching and learning the content Corporal Adventure Practices to students of the Elementary School final years. This is an experience report of a proposal to systematize the Corporal Adventure Practices elaborated and planned in a collaborative way among ten students of a Physical Education Degree course at a Brazilian Federal University, scholarship holders of the Institutional Scholarship Program of Initiation to Teaching, and two teachers. The application of this content took place in classes of 6 th and 7 th grade of elementary school in a public school. The result of the experience obtained in this process generated three categories: facilities and difficulties for teaching, experiences with the corporal practices of adventure teaching and learning of the students.
\end{abstract}

\title{
Keywords:
}

Corporal Practices of Adventure. Physical Education. PIBID. School.

\section{Introdução}

A questão sobre o que ensinar nas aulas de Educação Física sofreu e sofre ainda hoje alguns dilemas desde que esse componente foi inserido na escola. No entanto, observa-se que ao longo das décadas existiu, e ainda existe, a predominância dos conteúdos esportivos dentro da disciplina, especialmente o futebol, o basquetebol, o voleibol e o handebol (SILVA; BRACHT, 2012).

Durante a década de 1980, no chamado movimento renovador da Educação Física escolar (DARIDO, 2011), a hegemonia do esporte nas aulas foi algo bastante criticado por professores e pesquisadores da área. Conforme a perspectiva proposta pelo Coletivo de Autores, a Educação Física na escola deve tratar dos conteúdos vinculados à cultura corporal, sendo esses o esporte, o jogo, a luta, a dança e a ginástica (SOARES et al., 2012).

Desde então, diferentes propostas pedagógicas têm sido realizadas por professores das diversas regiões do Brasil, com o intuito de enriquecer as experiências e aprendizagens dos alunos na escola em relação aos conteúdos da Educação Física. Essas propostas abrem a possibilidade do ensino de novos conteúdos, oportunizando maior legitimação da Educação Física na escola, valorização do professor e motivação dos alunos para aprenderem.

Recentemente, com a publicação do documento da Base Nacional Comum Curricular (BNCC) (BRASIL, 2017), nota-se a ampliação das práticas corporais tematizadas nas aulas da Educação Física escolar, incluindo àquelas referidas pelo Coletivo de autores (SOARES et al., 2012), as Práticas Corporais de Aventura (PCAs). De acordo com a literatura, identifica-se que as PCAs são ainda pouco exploradas na disciplina em comparação com os conteúdos esportivos, tendo em vista, muitas vezes, a falta de conhecimentos dos professores sobre essa temática e a forma como apresentar aos alunos (MOURA et al., 2018).

Ao pensar nessa questão, foi desenvolvida uma proposta de sistematização das PCAs para ser ensinado nas aulas de Educação Física aos anos finais do Ensino Fundamental, com o intuito de auxiliar os professores a pensarem e organizarem propostas pedagógicas com esse conteúdo. Essa proposta foi desenvolvida por licenciados de Educação Física, bolsistas do Programa Institucional de Bolsas de Iniciação da Docência (PIBID), da Universidade Federal do Rio Grande - RS (FURG).

Sendo assim, o objetivo deste relato de experiência será o de apresentar as percepções dos pibidianos do curso de Educação Física da FURG sobre o processo de ensino e de aprendizagem das PCAs na escola. 


\section{As Práticas Corporais de Aventura e a Educação Física escolar}

Alguns autores têm defendido o ensino sistemático das PCAs nas aulas de Educação Física (ARMBRUST; SILVA, 2012; SILVA et al., 2016; INÁCIO et al., 2016; TAHARA; DARIDO, 2016). As diferentes modalidades desse conteúdo têm sido consideradas como um conteúdo emergente (ARMBRUST; SILVA, 2012), o qual se encontra como uma das unidades temáticas da Educação Física no documento da BNCC (BRASIL, 2017).

Pode-se encontrar na literatura outras denominações das PCAs, como: esportes de aventura, esportes de risco, esportes urbanos, esportes radicais, atividades físicas de aventura, atividades físicas de aventura na natureza, esportes na natureza, entre outros (INÁCIO et al., 2016; TAHARA; DARIDO, 2016). Apesar das diferentes formas encontradas para se falar das PCAs, todas têm em comum as seguintes características: a possibilidade de serem realizadas no espaço urbano ou na natureza, envolverem graus de risco, imprevisibilidade e perigo (INÁCIO et al., 2016).

Conforme Armbrust e Silva (2012), diversificar os conteúdos da Educação Física na escola é oportunizar aos alunos diferentes possibilidades de alcançarem a autorrealização, a satisfação, o autoconhecimento e o conhecimento de práticas saudáveis utilizadas nos momentos de lazer. Assim, quando o professor proporciona a aprendizagem sobre as PCAs na escola pode estar auxiliando no desenvolvimento de diferentes habilidades motoras (SILVA et al., 2016), além de estimular a reflexão e o debate de questões sobre o meio ambiente, a sustentabilidade e a preservação da natureza (TAHARA; DARIDO, 2016).

Ainda que a inserção das PCAs na escola encontre algumas dificuldades, são sugeridas por Tahara e Darido (2016) algumas modalidades possíveis de se ensinar nas aulas de Educação Física. Entre elas se encontra o cicloturismo ${ }^{1}$ na escola, o skate, o parkour ${ }^{2}$, o surfe, o slackline ${ }^{3}$, o trekking ${ }^{4}$, entre outros.

Em relação às dificuldades mencionadas, as PCAs, por se constituírem como conteúdo emergente, podem encontrar barreiras para se legitimar na escola. Destaca-se que a predominância do conteúdo esportivo nas aulas de Educação Física, apesar de bastante questionado nas últimas décadas, ainda resiste em detrimento de outras possibilidades de aprendizagem pelos alunos. Sendo assim, ter domínio de um conteúdo novo e apresentar aos alunos já acostumados com uma determinada realidade é sempre um desafio para o professor (ARMBRUST; SILVA, 2012; TAHARA; DARIDO, 2016).

Ademais, são apontadas outras dificuldades como o preço alto dos equipamentos e materiais para apresentar certas modalidades, a falta de espaço na escola, falta de qualificação e interesse docente, falta de sistematização para o ensino dessas práticas, entre outros (INÁCIO et al., 2016; MOURA et al., 2018; TAHARA; DARIDO, 2016).

No entanto, é importante incentivar os professores de Educação Física a ensinarem as PCAs, buscando alternativas possíveis de acordo com a realidade escolar e dos alunos, uma vez que as aulas com esse conteúdo poderão proporcionar aprendizagens novas, aulas prazerosas e diversificadas aos alunos (TAHARA; DARIDO, 2016). Ao mesmo tempo, Armbrust e Silva (2012) defendem que ensinar na escola esse conteúdo pode proporcionar que os alunos se coloquem em situações com certo nível de risco, aprendendo dessa forma a gerenciarem o medo e buscarem alternativas para superarem os níveis de imprevisibilidade das atividades.

\footnotetext{
1. O cicloturismo é uma prática que utiliza como elemento principal a bicicleta para a realização de diferentes percursos no meio urbano ou na natureza (ABNT, 2007)

2. O parkour pode ser entendido como uma prática caracterizada pela realização de movimentos corporais com o objetivo de passar por obstáculos no meio urbano, utilizando saltos e aterrissagens (ALVES; CORSINO, 2013).

3. O slackline é uma prática de equilíbrio em que as manobras são realizadas sobre uma fita de nylon, de 2,5 a 5 centímetros de largura, esticada entre dois pontos fixos em alturas variadas do solo (PEREIRA, 2013).

4. O trekking é descrito por Franco, Cavasini e Darido (2017) como uma atividade relacionada à caminhada usualmente realizada em trilhas e espaços naturais.
} 


\section{Sistematização do ensino das PCAs}

De acordo com o item acima, entende-se que pelas PCAs não serem conteúdos tradicionais de ensino nas aulas de Educação Física, diferentes propostas de como o ensinar precisam ser divulgadas na literatura de forma a compartilhar diferentes experiências entre os professores. Sendo assim, neste relato de experiência, apresenta-se uma possibilidade de sistematização e ensino desse conteúdo para alunos dos anos finais do Ensino Fundamental.

Entende-se a sistematização dos conteúdos como uma forma de organizar os conhecimentos que servirão de base para o ensino aos alunos (LIBÂNEO, 2013). Enquanto que os conteúdos curriculares são entendidos para além de fatos, conceitos e princípios (DARIDO, 2011), mas, segundo Libâneo (2013, p. 141), “[...] são o conjunto de conhecimento, habilidades, hábitos, modos valorativos e atitudinais de atuação social, organizados pedagógica e didaticamente, tendo em vista a assimilação ativa e aplicação pelos alunos na sua prática de vida”.

Dessa forma, este trabalho foi escrito com base em uma ação realizada pelo grupo PIBID Educação Física da FURG, a qual teve seu início no segundo semestre letivo do ano de 2019. Nesse momento o grupo PIBID, protagonista deste trabalho, era formado por uma coordenadora, docente do curso de Licenciatura em Educação Física, um supervisor, professor de Educação Física da escola parceira do programa, e 10 pibidianos, estudantes do curso de Licenciatura em Educação Física. Nesta escrita, os estudantes serão denominados pela letra "E" de estudante seguida de um número para caracterizar cada um (E1, E2, E3, E4, E5, E6, E7, E8, E9, E10).

A escola parceira do programa se caracterizava como uma instituição de ensino pública pertencente à rede municipal de ensino. Localizada na zona urbana da cidade, oferece turmas de Educação Infantil e do $1^{\circ}$ ao $9^{\circ}$ ano do Ensino Fundamental. O professor supervisor, formado em Licenciatura em Educação Física, no ano de participação no programa, estava responsável por ministrar a disciplina para três turmas de $6^{\circ}$ ano e duas turmas de $7^{\circ}$ ano do Ensino Fundamental.

Para iniciar as atividades na escola, o grupo planejou o ensino de duas modalidades esportivas aos alunos. As modalidades escolhidas foram o voleibol aos alunos do $6^{\circ}$ ano e o basquetebol aos do $7^{\circ}$ ano. Ao elaborar esse planejamento, a intenção era oportunizar aos alunos o aprendizado sistemático dessas modalidades. No entanto, o grupo não precisou esperar o final da execução das aulas planejadas com esses conteúdos para avaliar a falta de interesse e desmotivação de muitos alunos nas aulas de Educação Física.

De acordo com Silva e Bracht (2012), uma das práticas pedagógicas em voga nas aulas de Educação Física, resume-se ao fato do professor organizar seu ensino acreditando que sua função é promover a prática dos esportes tradicionais, como o voleibol, basquetebol, handebol e futsal/futebol. O predomínio das atividades esportivas em detrimento do ensino de outros conteúdos nas aulas de Educação Física pode provocar a falta de interesse de aprendizagem pelos alunos, conforme demonstram os resultados de alguns estudos (CHICATI, 2000; REZER, 2007).

De forma a buscar maior interesse pelos alunos nas aulas de Educação Física, o grupo aqui referido, decidiu estudar e organizar o ensino de um conteúdo emergente dentro desse componente. Então, a escolha pelas PCAs se justificou por ser um conteúdo ainda pouco explorado pelo professor e pouco conhecido pela maioria dos alunos da escola.

Tendo em vista o tempo de aulas disponível para o ensino desse conteúdo, o grupo optou por ensinar as modalidades de skate, surfe e parkour. Posto isso, antes da elaboração dos planos de aula, o grupo estudou sobre essas diferentes modalidades, montou um cronograma, sistematizando o ensino de cada uma, e pesquisou atividades apropriadas para o alcance dos objetivos de cada aula.

A busca pelas atividades levou em consideração, especialmente, a realidade dos alunos e as condições físicas e materiais da escola. Em relação aos alunos, apesar da maioria saber que existe as diferentes modalidades escolhidas, não tinham tido ainda experiências práticas com o conteúdo. Sobre o local, a escola dispunha de um espaço físico com duas quadras poliesportivas e um pátio com areia e árvores, ambos sem cobertura. No que tange aos materiais, a escola não disponha de skates, pranchas de surfe e nem equipamentos de segurança para a prática do parkour. 
Para elaborar o cronograma o grupo contou o número de aulas de Educação Física para as turmas de $6^{\circ}$ e $7^{\circ}$ ano, entre os meses de setembro e dezembro de 2019. A previsão era de 17 aulas para cada turma, sendo duas por semana com 45 minutos de duração cada. No cronograma, a primeira aula foi reservada para a introdução sobre o conteúdo das PCAs. O objetivo dessa aula foi apresentar de forma expositiva o que são as PCAs, as principais características, o histórico, escutar sobre o que os alunos já conheciam das diferentes modalidades e realizar duas atividades práticas com o intuito de vivenciarem PCAs urbanas e na natureza.

Posteriormente, a primeira modalidade ensinada foi o surfe. A escolha dessa modalidade levou em consideração a localização geográfica da cidade em que a escola está localizada. Essa se localiza em um município litorâneo em que a prática do surfe é frequente nos meses de verão e outono, com a presença de escolas de surfe para crianças e adolescentes. Foram planejadas seis aulas para o ensino dessa modalidade. Entre os temas desenvolvidos foi apresentado o histórico do surfe, introduzido movimentos básicos, confeccionadas pranchas de papelão e oferecida uma palestra aos alunos com um instrutor de surfe da cidade. Para ensinar essa modalidade, houve o empréstimo de pranchas, por parte de alguns integrantes do PIBID, assim como foram utilizadas as pranchas confeccionadas pelos alunos. Destaca-se que todas as atividades relacionadas ao surfe, e das demais modalidades, foram desenvolvidas na própria escola devido à falta de recursos financeiros para a contratação de um veículo para transporte dos alunos, professores e pibidianos para outros locais da cidade.

Em seguida, dando continuidade ao ensino das PCAs, na oitava aula o grupo introduziu uma nova modalidade, o skate. Inicialmente, paralelo ao histórico da prática, os alunos foram desafiados a buscarem semelhanças entre a prática do surfe e do skate. Na sequência, foram ensinados os principais movimentos e algumas manobras realizadas. Para o ensino dessa modalidade, houve o empréstimo de skates pelos alunos da escola e pelo curso de Educação Física dos pibidianos, assim como a utilização de plataformas de equilíbrio construídas com garrafas pets.

Por fim, para a décima terceira aula estava planejado o ensino do parkour. No entanto, devido à demora necessária para os alunos confeccionarem as pranchas de surfe, os cancelamentos de aula em função dos dias de intensa chuva na região e outras atividades/eventos promovidas pela escola, esse conteúdo não foi desenvolvido.

Consequentemente, a última aula do trimestre foi antecipada e o grupo realizou junto aos alunos o encerramento do conteúdo com base na experiência de algumas atividades práticas e conversa, avaliando as aprendizagens realizadas.

De maneira a seguir o cronograma elaborado, para cada aula foi redigido um plano pelo professor supervisor, utilizando as atividades previamente selecionadas pelo grupo, o qual foi enviado, via grupo online em uma rede social, com 24 horas de antecedência do início da aula. Os estudantes se dividiram em duplas para auxiliarem o professor supervisor na execução do plano de aula em cada turma.

No final das atividades programadas pelo grupo no ano de 2019, foi proposta uma avaliação aos pibidianos em relação ao ensino das PCAs na escola. Os principais resultados dessa avaliação são apresentados a seguir.

\section{Análise dos resultados da intervenção}

Com base na análise e avaliação das experiências do grupo com a sistematização e ensino das PCAs, são apresentados os resultados deste trabalho por meio da criação de três categorias: 1) Facilidades e dificuldades para o ensino, 2) Experiências com o ensino das PCAs e 3) Aprendizagem dos alunos.

Em relação à primeira categoria, observa-se que no decorrer da atuação pedagógica na escola, os estudantes enfrentaram momentos, percebidos por eles, como facilitadores ou desafiadores para o ensino das PCAs. Sobre as facilidades, E1 e E5 destacaram que as experiências anteriores dos alunos e a presença das modalidades das PCAs na cidade, como o surfe, tornaram o ensino mais fácil: "Os alunos facilitaram 
o ensino das PCAs pois foram mais receptivos do que eu estava esperando [...]" (E1) e "Acredito que as facilidades vieram da vivência que muitos alunos já possuíam fora da escola com o skate e o surfe, além do fato de termos na cidade uma prática bem acentuada" (E5).

Para Batista e Moura (2019), os quais discutem sobre alguns princípios metodológicos para o ensino da Educação Física, um dos processos que pode facilitar as aprendizagens é a valorização, pelos professores, das experiências e conhecimentos já adquiridos pelos alunos dentro e fora da escola. Isso não significa, como coloca Libâneo (2013), que o professor vai simplificar e exigir menos, mas adequar o ensino de forma que o conteúdo seja mais compreensível e assimilado pelos alunos.

Outro fator que pode ter colaborado com o processo de ensino das PCAs foi à apropriação teórica do conteúdo pelos futuros professores, a organização didática das aulas e a ajuda mútua entre os participantes do grupo PIBID. Percebem-se tais potencialidades por meio dos relatos dos estudantes (E2, E3, E6 e E4): “Deu super certo, na minha opinião, porque nós todos estudamos e nos dedicamos para tornar aquele conteúdo algo novo pra eles [alunos] mesmo que alguns já conhecem o skate ou o surf [...]" (E2), “[...] o que facilitou foi ter estudado e pesquisado sobre as atividades que poderiam ser trabalhadas na escola" (E3), "O estudo do material e o planejamento foram os principais facilitadores para ensinar as PCAs [...]" (E6) e "O que facilitou foi o empenho e ajuda mútua dos colegas de projeto. Pois a maioria encontrava-se na mesma posição: sem ter praticado anteriormente surf ou skate" (E4).

O conhecimento do conteúdo é um dos pontos fundamentais da prática pedagógica. Conforme Silva et al. (2016), existe a necessidade de maior aprofundamento sobre o conteúdo das PCAs na formação dos professores de Educação Física, uma vez que esse não aparece como um conteúdo tradicional. Ao mesmo tempo, além da apropriação teórica, o professor precisa desenvolver competências necessárias para o ensino, como a organização de um planejamento. Observa-se que o grupo PIBID conseguiu elaborar o plano e utilizar estratégias de ensino contextualizadas com a realidade da escola, de forma a facilitar a aprendizagem dos alunos.

Ao mesmo tempo, paralelo a conhecimento do conteúdo, a elaboração do planejamento e uso de estratégias, o professor precisa saber lidar com as incertezas que envolvem a atuação pedagógica (SILVA et al., 2016). Sendo assim, os estudantes destacaram algumas dificuldades encontradas durante as aulas, como a falta de organização da escola e a resistência de alunos ao conteúdo novo. Os relatos a seguir demonstram tais desafios: "[...] a demanda da escola com outras atividades atrapalhou o ensino do conteúdo, seja com falta de aulas, períodos reduzidos ou falta de apoio e estrutura psicológica do ambiente" (E1), "A rotina da escola foi o que mais nós prejudicou [...]" (E2), "[...] a aceitação do novo para alguns alunos, a questão da rotina escolar e também o clima que inviabilizou muito esse $2^{\circ}$ semestre" (E5) e "[...] os contras é o fato da segurança dos alunos, não apoio da escola, receio dos alunos ao novo [...]" (E6).

Os desafios mencionados podem ser concebidos como momentos de aprendizados para os futuros professores. Segundo Caparroz e Bracht (2007), egressos dos cursos de licenciatura em Educação Física tendem a sentir dificuldades em relação à atuação na escola quando formados. A explicação dos autores para esse fato é a insuficiência, durante os anos de graduação, de diferentes experiências favoráveis à construção de conhecimentos, como os didáticos e do conteúdo, os quais garantem maior segurança à atuação pedagógica.

Em relação às experiências dos estudantes com o ensino das PCAs, além das situações favoráveis e dos desafios apontados na categoria anterior, os pibidianos destacaram fatos que contribuíram para considerar essa uma experiência marcante na formação. Eles relataram a oportunidade de perceber o quanto é possível ensinar conteúdos não tradicionais nas aulas de Educação Física, conforme colocam E1 e E4, quando dizem:

A experiência com o ensino das PCAs na escola foi enriquecedora, tanto na parte profissional quanto pessoal, pois permitiu que eu pudesse experimentar outros conteúdos além dos esportes hegemônicos que eram fortemente trabalhados durante a minha escolarização. Sendo também uma experiência facilitadora para futuras atuações na escola, seja em estágios ou fora da formação acadêmica. (E1). 
Foi desafiador. Pois sabemos que se trata de um conteúdo que abrange modalidades onde a experiência prévia ajuda demais para o desenvolvimento e ensino. No entanto, mesmo sem essas vivências nas modalidades das PCAs, como surfe e skate, acabamos nos saindo bem. Mostra que mesmo contra essas adversidades e desafios é possível abraçarmos e disponibilizarmos esses conhecimentos para os alunos. (E4).

Assim como se percebe no final do relato de E4, E2 menciona que proporcionar o ensino de novos conteúdos para os alunos nas aulas de Educação Física exige a aquisição de novos conhecimentos e vontade por parte dos professores: "Foi bem interessante, me mostrou que é possível desenvolver muitos conteúdos da Educação Física na escola desde que tenha estudo e vontade por parte do professor” (E2).

Ao mesmo tempo, essa experiência possibilitou aos futuros professores maior confiança e motivação para ensinar aos alunos conteúdos pouco familiares: "Foi muito gratificante participar do projeto de ensino das PCAs, pois é motivador tendo em vista que é pouco explorado pelos professores de Educação Física do Município" (E5).

A experiência de trabalhar com as PCAs foi única, pois com certeza foi um momento de muito aprendizado, pois como este é um novo conteúdo a ser tralhado na escola, segundo a BNCC, quando eu me formar e for atuar na escola esta será uma atividade que irei tirar de letra, pois não serei pega de surpresa [...]. (E3).

Logo, por meio das palavras utilizadas pelos estudantes, como gratificante, desafiador, enriquecedora, interessante e experiência única, nota-se que participar de todo o processo que envolveu a organização do ensino de um conteúdo, vivenciando possibilidades e limitações, foi um momento formativo significativo para esses licenciandos. Destaca-se a possiblidade de perceberem como as aulas de Educação Física podem oportunizar aprendizagens diversas aos alunos, para além dos conteúdos esportivos (TAHARA; DARIDO, 2016).

Dessa forma, na categoria aprendizagem dos alunos, os estudantes apontaram como um dos resultados das aulas a aprendizagem, ou experiência, dos alunos com o conteúdo das PCAs. Isso é demonstrado nas avaliações realizadas por E1, E4 e E6: "Sim, os alunos não sabiam o que era PCAs, mesmo que alguns deles já realizassem alguma atividade relacionada [...]" (E1), "Para os alunos acredito que a experiência seja mais importante, pois além de saírem da mesmice, puderam ser instigados com novos conhecimentos [...]” (E6),

Só o fato de ser uma proposta que não aborde os 4 esportes tradicionais trabalhados na escola, já é uma novidade. Ademais, aprenderam que nem tudo na aula de Educação Física é competição. A cooperação entre eles deve ser fomentada com esse tipo de conteúdo. Haja vista que se trata de uma prática onde a maioria não tinha tido contato com as modalidades de aula. (E4).

Ademais, alguns estudantes destacaram os temas discutidos nas aulas que mais chamaram à atenção dos alunos para aprender. E2 e E5 mencionam os aspectos históricos e particulares de cada modalidade, além do respeito, da cooperação e do desafio proporcionado nas aulas: "Sim, a história e a luta que existe por trás das duas práticas desenvolvidas e algumas curiosidades que partiam deles também, e nós também aprendemos muito com eles" (E2) e

Sim, curiosidades e histórias das práticas foi bem trabalhado pelo grupo, esse aprendizado eles com certeza levarão consigo. Além de respeito, cooperação e desafios que tiveram, e que acredito serem fundamentais para uma base de vida, da inclusão, pois muitos não haviam tocado em um skate ou uma prancha de surf. (E5).

Da mesma forma, E3 destaca a oportunidade de os alunos estarem em contato com os equipamentos utilizados para a prática de algumas modalidades, como o skate, fato que diversificou as aulas: "Sim, muitos tinham medo de subir em um skate, logico não saíram andando logo de cara mas foi um avanço para muitos a questão de ter subido em um" (E3). 
Compreende-se que as atividades programadas pelo grupo PIBID, com as PCAs, oportunizaram aos alunos da escola diferentes aprendizagens, ou experiências, as quais não se deteram em proporcionar apenas vivencias práticas das modalidades apresentadas. Ao permitirem o conhecimento da história, das curiosidades, dos equipamentos e desafiar os alunos a experimentarem e aprenderem novas habilidades motoras presentes nas atividades oferecidas, o grupo pode contribuir com a aprendizagem de conceitos e atitudes que caracterizam esse conteúdo.

Historicamente, as aulas de Educação Física privilegiam o desenvolvimento da dimensão procedimental dos conteúdos em detrimento das dimensões conceitual e atitudinal (DARIDO, 2011). As características procedimentais, conceituais e atitudinais dos conteúdos podem ser entendidas conforme Zabala (1998), o qual as propõe no sentido de oportunizar uma maior abrangência do ensino na escola. Dessa forma, a dimensão conceitual se refere àquilo que o aluno deve saber em termos dos conceitos de um conteúdo, a dimensão procedimental está relacionada com aquilo que o aluno deve saber fazer sobre o conteúdo aprendido e a dimensão atitudinal atribui os valores e atitudes que o aluno deve construir baseado no conteúdo apresentado.

A oportunidade dos alunos aprenderem os conteúdos a partir dessas três dimensões contribui para sua formação integral, sendo esse um dos objetivos da educação básica no Brasil. Segundo as Diretrizes Curriculares Nacionais Gerais para a Educação Básica (BRASIL, 2013), as quais estabelecem as bases comuns gerais para a Educação Infantil, Ensino Fundamental e Médio no país, as três etapas da educação escolarizada devem oferecer condições para o desenvolvimento do aluno nos aspectos físico, afetivo, psicológico, intelectual e social.

A proposta encontrada no estudo de Pereira e Armust (2010) corrobora com o ensino das PCAs, oferecido pelo grupo PIBID. Os autores propõem que os conteúdos das PCAs devem ser ensinados pelos professores a partir das três dimensões dos conteúdos. Em relação aos conteúdos conceituais abordar sobre o histórico das modalidades, equipamentos, atletas famosos, locais de prática e discussões sobre a temática do meio ambiente (sustentabilidade, preservação, etc.). Sobre os conteúdos procedimentais, enfatizar as técnicas de movimento e segurança, adaptações de cada modalidade aos contextos e idades e condições possíveis de se praticar na escola. E, nos conteúdos atitudinais, aprender sobre o respeito às normas de segurança, ética, relações sociais e psicológicas inerentes à prática (cooperação, coragem, gestão de conflitos, etc.).

Sendo assim, este trabalho não pretendeu apresentar um manual ou uma receita pronta do que o professor de Educação Física deve fazer e ensinar sobre o conteúdo das PCAs. Uma das intenções foi de dar pistas e refletir sobre o ensino e a aprendizagem desse conteúdo nas aulas desse componente curricular para os anos finais do Ensino Fundamental.

\section{Considerações finais}

De acordo com objetivo deste relato de experiência e da proposta de ensino das PCAs organizado e aplicada pelo grupo PIBID aos alunos de uma escola, pode-se pensar os resultados dessa ação por meio de três categorias: facilidades e dificuldades para o ensino, experiências com o ensino e aprendizagem dos alunos.

Infere-se que os resultados presentes nessas categorias sinalizam potencialidades do trabalho com as PCAs na escola a partir da percepção dos pibidianos do grupo PIBID Educação Física. Ao analisar-se pelo viés da formação inicial dos professores, a experiência com o ensino desse conteúdo possibilitou o planejamento e sequenciamento das atividades, além do contato direto com os alunos. Esse contato próximo oportunizou aos futuros professores experimentarem desafios e perceberem possibilidades na prática pedagógica com as modalidades das PCAs nas aulas de Educação Física.

Ao mesmo, tiveram a chance de conhecer algo novo e mudar concepções antigas sobre o ensino da Educação Física escolar. Perceberam que os conteúdos desse componente extrapolam a simples execução prática de alguns esportes tradicionais e que podem contribuir com aprendizagens mais significativas dos 
alunos na escola. No decorrer da ação, o grupo PIBID procurou ensinar as PCAs tendo como base as três dimensões que caracterizam os conteúdos, contribuindo com a construção de conceitos, com o aprender a executar habilidades motoras e a respeitar e valorizar atitudes, como a cooperação nas aulas.

Os resultados deste relato de experiência indicam que as PCAs são um conteúdo possível de se ensinar nas aulas de Educação Física e podem contribuir para o aprendizado e desenvolvimento integral dos alunos. No entanto, destaca-se que mais trabalhos como esse precisam ser realizados e socializados na literatura. Acredita-se que dessa forma, os professores terão conhecimentos de diferentes possibilidades de se ensinar as PCAs nas aulas de Educação Física, construindo seus próprios planejamentos, adequados a cada contexto de intervenção.

\section{Referências}

ALVES, Carla da Silva Reis; CORSINO, Luciano Nascimento. O parkour como possibilidade para a Educação Física escolar. Motrivivência, Florianópolis, ano XXV, n. 41, p. 247-257, 2013.

ARMBRUST, Igor; SILVA, Sheila Aparecida Pereira dos Santos. Pluralidade cultural: os esportes radicais na educação física escolar. Movimento, Porto Alegre, v. 18, n. 1, p. 281-300, 2012.

ASSOCIAÇÃO BRASILEIRA DE NORMAS TÉCNICAS (ABNT). NBR 15509-1: cicloturismo parte 1 - requisitos para produto. Rio de Janeiro, 2007.

BATISTA, Cleyton; MOURA, Diego Luz. Princípios metodológicos para o ensino da educação física escolar: o início de um consenso. Journal of Physical Education, Maringá, v. 30, n. 1, e3041, 2019.

BRASIL. Diretrizes Curriculares Nacionais da Educação Básica. Brasília, DF: MEC/SEB/DICEI, 2013.

BRASIL. Base Nacional Comum Curricular. Brasília: MEC, 2017.

CAPARROZ, Francisco Eduardo; BRACHT, Valter. O tempo e o lugar de uma didática da Educação Física. Revista Brasileira de Ciências do Esporte, Campinas, v. 28, n. 2, p. 21-37, 2007.

CHICATI, Karen Cristina. Motivação nas aulas de Educação Física no ensino médio. Revista da Educação Física, Maringá, v. 11, n. 1, p. 97-105, 2000.

DARIDO, Suraya Cristina. Os conteúdos da educação física na escola. In: DARIDO, Suraya Cristina; RANGEL, Irene Conceição Andrade. Educação física na escola: implicações para a prática pedagógica. Rio de Janeiro: Guanabara Koogan, 2011. p. 64-79.

FRANCO, Laércio Clara Pereira; CAVASINI, Rodrigo; DARIDO, Suraya Cristina. Práticas corporais de aventura. In: GONZÁLES, Fernando Jaime; DARIDO, Suraya Cristina; OLIVEIRA, Amauri Aparecido Bássoli de Oliveira (org.). Lutas, capoeira e práticas corporais de aventura. Maringá: Eduem, 2017. p. 137- 190.

INÁCIO, Humberto Luís de Deus et al. Práticas corporais de aventura na escola: possibilidades e desafios - reflexões para além da Base Nacional Comum Curricular. Motrivivência, Florianópolis, v. 28, n. 48, p. 168-187, 2016.

LIBÂNEO, José Carlos. Didática. 2. ed. Brasília, DF: Cortez, 2013.

MOURA, Diego Luz et al. Dialogando sobre o ensino da Educação Física: práticas corporais de aventura na escola. Curitiba: CRV, 2018.

PEREIRA, Dimitri Wuo. Slackline: vivências acadêmicas na educação física. Motrivivência, Florianópolis, ano XXV, n. 41, p. 223-233, 2013.

PEREIRA, Dimitri Wuo; ARMBRUST, Igor. Pedagogia da aventura: os esportes radicais, de aventura e de ação na escola. Jundiaí: Fontoura, 2010.

REZER, Ricardo. Relações entre conhecimento e prática pedagógica no campo da Educação Física: pontos de vista... Motrivivência, Florianópolis, ano XIX, n. 28, p. 38-62, 2007.

SILVA, Bruno Allan Teixeira da et al. Atividades de aventura na Licenciatura em Educação Física: um relato de experiência. Cadernos de Formação RBCE, Porto Alegre, v. 7, n. 1, p. 69-80, 2016.

SILVA, Mauro Sérgio; BRACHT, Valter. Na pista de práticas e professores inovadores na Educação Física escolar. Revista Kinesis, Santa Maria, v. 30, n. 1, p. 80-94, 2012. 
SOARES, Carmen Lúcia et al. Metodologia do ensino da Educação Física. 2. ed. São Paulo: Cortez, 2012.

TAHARA, Alexander Klein; DARIDO, Suraya Cristina. Práticas corporais de aventura em aulas de educação física na escola. Conexões: Educação Física, Esporte e Saúde, Campinas, v. 14, n. 2, p. 113-136, 2016.

ZABALA, Antoni. A prática educativa: como ensinar. Porto Alegre: Artmed, 1998.

Data de submissão: 18/05/2020

Data de aceite: $08 / 07 / 2020$ 